\title{
A MUTILAÇÃO GENITAL FEMININA NO \\ CONTINENTE AFRICANO SOB A PERSPECTIVA FEMINISTA
}

\author{
FEMALE GENITAL MUTILATION IN THE \\ AFRICAN CONTINENT IN THE FEMINIST PERSPECTIVE
}

\begin{abstract}
Resumo
O presente artigo apresenta como objetivo principal fazer uma análise feminista da mutilação genital feminina, prática que fere os direitos fundamentais de grande parte da população feminina africana. Esta pesquisa foi dividida em três partes, sendo que em um primeiro momento será apresentada a Teoria Feminista (teoria que servirá de balizadora da análise feita posteriormente). Após será exposta a prática, procurando compreender no que essa consiste, assim como o seu histórico, as suas justificativas para sua a perpetuação e por fim as consequências físicas e emocionais para essas mulheres. Na última parte do artigo será então feita a análise proposta no objetivo do estudo. Faz-se uso de uma metodologia de análise documental e bibliográfica a partir de leituras de documentos oficiais apresentados pelas agências da Organização das Nações Unidas. Esta pesquisa mostra-se relevante devido à perspectiva feminista ainda ser marginalizada perante de teorias mainstream.
\end{abstract}

Palavras-chave: Mutilação Genital Feminina. Teoria Feminista. Direitos Humanos. África.

\begin{abstract}
The main objective of this article is to make a feminist analysis of female genital mutilation, which endangers the fundamental rights of a large part of the African population. This research was divided into three parts, in the first one will be presented the Feminist Theory (which will serve as the theoretical framework of the analysis). After, the practice will be exposed, with the aim of understanding its basic tenets, as well as its history, its justifications for its perpetuation and finally the physical and emotional consequences for women. In the last part of the article will be made the proposed analysis in the objective of the study. A methodology of documentary and bibliographic analysis will be used from readings of official documents presented by the agencies of the United Nations. This research is relevant because the feminist perspective is still marginalized in the mainstream theories.
\end{abstract}

Keywords: Female Genital Mutilation. Feminist Theory. Human Rights. Africa.

Letícia Zimmer Olegário

Universidade de Santa Cruz do Sul - UNISC.

E-mail: leticia.zimmer.o@gmail.com

Mariana Dalalana Corbellini

Universidade de Santa Cruz do Sul - UNISC.

E-mail: mariana.corbellini@gmail.com 


\section{Introdução}

A Organização Mundial da Saúde - WHO, sigla em inglês (1997) define a mutilação genital feminina (MGF) como todo e qualquer procedimento que acabe por ferir a genitália das mulheres. Por ser um tema bastante polêmico, gera acalorados debates dentro e fora da Academia. Por um lado, tem-se que esta prática fere os direitos das mulheres por ser uma violência direta sobre seus corpos e autonomia. Por outro, o relativismo cultural defende a soberania dos povos sobre seus valores e tradições.

O Feminismo, em suas muitas vertentes, traz como visão básica a defesa da autonomia dessas mulheres, entre outras reivindicações, ou seja, essas devem ser capazes de escolher livremente sobre seus corpos, assim como sobre os de suas filhas. Quando se fala em uma escolha completamente livre, significa uma escolha desprendida de julgamentos e pressões externas da sociedade sobre elas. Quando essas consentem com a prática, esta permissão deve ser verdadeira e livre da pressão social para que os seus corpos atendam as expectativas da comunidade.

Os direitos das mulheres adentraram a agenda internacional por volta da década de 1970, com a Convenção sobre a Eliminação de Todas as Formas de Discriminação Contra as Mulheres - CEDAW, sigla em inglês (Organização das Nações Unidas - ONU, 1979). Esta convenção foi uma das primeiras a determinar o que é a discriminação contra a mulher, advogando para que os países signatários começassem a tomar medidas em prol da defesa dos direitos femininos.

O objetivo principal deste artigo é lançar um olhar feminista para uma prática que se mostra sexista nos costumes e tradições de uma vasta população. Este estudo está divido em três partes principais. Em um primeiro momento será feita uma revisão teórica do Feminismo, assim como dos direitos das mulheres. Posteriormente será abordada a questão da mutilação genital feminina, sendo exposto no que consiste a prática, seu histórico, as justificativas para a perpetuação da MGF e as consequências físicas e emocionais para as mulheres mutiladas. Por fim, será feita uma análise feminista sobre os dados obtidos em relatórios oficiais de agências da ONU, assim como de outros autores que contribuíram para o estudo da mutilação genital feminina.

\section{Feminismo}

Segundo Sondra Farganis (1994), Feminismo é uma ideologia ou um sistema de crenças; um conjunto integrado de pressupostos teóricos que, quando analisados, estruturam uma cosmovisão que é tida como verdade pelos seus adeptos. Uma das bases desta teoria tão diversa é a crença de que é errado e injusto tratar homens e mulheres com desigualdade. Se analisada a história mundial, percebe-se como a população feminina tem sido oprimida ao longo dos séculos, através de um sistema patriarcal, que legitima e apoia essa repressão/submissão.

O termo patriarcado vem, originalmente, dos sistemas de parentescos das sociedades mais antigas, segundo Adriana Piscitelli (2002), porém, hoje este conceito é sinônimo de dominação, assim como no imperialismo e no colonialismo, sendo, no patriarcado, o poder detido apenas pelos homens. A opressão, que é característica desse sistema, vem das relações sociais pré-estabelecidas, e seria "um sistema político quase místico, invisível, [...], cujo propósito seria oprimir as mulheres" (Piscitelli, 2002: 13), sendo este conceito relevante para a compreensão dos estudos feministas. É importante destacar que estes sistemas também contribuíram consideravelmente para a situação atual da mulher pós-colonial, tendo em vista que dificultou as conquistas de direitos fundamentais, tanto para a população feminina quanto masculina. Muito grupos feministas em países pós-coloniais ainda lutam por igualdade de direitos entre homens e mulheres.

A Teoria Feminista é bastante diversa e possui diferentes vertentes, devendo ser questionado se essa deve ser descrita como um conjunto de teorias ou se é possível classificá-la como uma única, permeando os mais diversos campos do conhecimento. Neste estudo, parte-se de um ponto de vista feminista Ocidental e Pós-colonial, buscando uma unidade destas reivindicações e visões de mundo. A base destes feminismos está na busca pela igualdade de oportunidades entre homens e mulheres, seja no campo político, econômico, cultural ou social, devendo ser revista qualquer ação que vá de encontro à esta definição.

Charlotte Krolokke \& Anne Scott Sorensen (2005) colocam que a história do feminismo é comumente dividida em três fases distintas, por uma questão de cronologia, mas também para diferenciar as reivindicações feitas por ativistas feministas nestes determinados 
períodos. A primeira onda do feminismo ocorreu na Europa, no final do século XIX e início do século XX e está conectada principalmente com o movimento liberal feminista, porém alguns acadêmicos ligam esta fase com o início do feminismo socialista também. As principais preocupações e reivindicações dessa fase foram quanto ao acesso e à igualdade de oportunidades, como o sufrágio universal. Uma das apreensões desse estágio foi quanto à igualdade de gênero e a busca por uma legislação que não discriminasse as mulheres (Krolokke \& Sorensen, 2005).

O movimento liberal feminista, segundo Izadora Monte (2013), enfoca na reversão das desigualdades entre gêneros e hierarquias. Esta corrente acredita que a opressão das mulheres se dá em função das barreiras legais dos Estados, o que impediria a realização plena dos direitos individuais. Este movimento luta pela liberalização da mulher. Quanto às feministas socialistas, essas viam nas diferenças das condições econômicas e materiais a origem da opressão feminina, visto que a população feminina não acrescentava economicamente na sociedade, sendo esta a fonte do patriarcado. Apesar dos movimentos se diferenciarem quanto às suas crenças, ambos reivindicam a igualdade entre gêneros, assim como uma maior liberdade política e econômica para a mulher.

A segunda onda feminista surgiu no pós-Segunda Guerra Mundial, já nos Estados Unidos da América (EUA), e o marco inicial foi o livro A Mística Feminina, de Betty Friedan. Neste livro, Friedan (2001) analisa a construção da imagem da mulher americana, causando impacto na sociedade burguesa americana. Este período trouxe como lema o pessoal é político, termo cunhado pela feminista Carol Hanisch (1970) e que vai ao encontro do efeito causado pelo livro de Friedan (2001). Neste momento, nos EUA, começaram a serem realizadas muitas reuniões femininas, em bairros e sindicatos e Hanisch (1970) indica que esses encontros eram uma forma de serem debatidos temas como política, além de mobilizarem-se para lutar pelos direitos femininos. Em suma, esta fase ficou conhecida por um feminismo mais radical com o movimento da liberação feminina, tendo seus ensaios com ênfase nos sentimentos, experiências e emoções das mulheres, de acordo com Farganis (1994) e verificado também nas autoras Friedan (2001) e Hanisch (1970).

Por fim, tem-se a última fase do feminismo, ou a terceira onda feminista, como ficou conhecida.
Apesar de no Ocidente, este período já ter começado com alguns dos privilégios conquistados durante as primeiras fases, essas ainda estão sendo reivindicadas em muitos países, principalmente aqueles que passaram pelo processo do colonialismo. Esta última onda surgiu por volta de 1990 e busca uma igualdade prática entre os gêneros, maior participação política e maior liberdade pessoal. Farganis (1994) argumenta sobre a aproximação entre o Feminismo, o Pós-modernismo e o Pós-colonialismo durante esta fase. Estas teorias agregaram ao Feminismo no sentido de terem trazido à tona a questão da mulher negra e da pós-colonial, assim como trouxeram uma preocupação com a identidade e a individualidade da mulher, reconhecendo as diferenças existentes entre cada uma delas, ao invés de tentarem unificar e excluir a individualidade de cada grupo. Muitas acadêmicas argumentam que essa fase ainda está em voga, enquanto outras denominam de pósfeminismo o período atual Ocidental.

Segundo Ana Gabriela Macedo (2006), o pósfeminismo, ao mesmo tempo em que reafirma as ditas conquistas das três primeiras ondas do feminismo, também vê a necessidade de fortalecê-lo, fazendo com que as mulheres se integrem ao movimento. Macedo (2006: 814), citando Macedo e Ana Luísa Amaral (2005) traz que o pós-feminismo traduz a multiplicidade de feminismos, recusando a superioridade de um sobre outro, porém, sem "pretender fazer tábula rasa das batalhas ganhas" das mais diversas facetas do movimento.

A partir de 1990 o feminismo deixou de ser centrado especificamente na mulher e em conseguir uma igualdade entre os gêneros, para concentrar-se na individualidade e diversidade de cada um, combatendo o patriarcado, visto que este impede o desenvolvimento da mulher. Segundo Tickner (2013: 276), "o conceito chave de todos os tipos de Teoria Feminista tem sido explicar a subordinação da mulher e a assimetria injustificada entre as posições sociais e econômicas dos homens e mulheres e achar a fórmula para acabar com tal". A maneira como ocorre a perpetuação da desigualdade de gênero é uma das principais questões a serem feitas para descobrir como o sistema internacional contribui para manter essa subordinação e assimetria. Essa também é uma questão válida quando analisada a perpetuação da mutilação genital feminina, visto que mulheres ainda são submetidas à prática apesar desta mutilar seus corpos e ferir seus direitos. 


\section{Direitos das Mulheres}

Os direitos fundamentais apresentam algumas características básicas, são elas: imprescritibilidade, inalienabilidade, irrenunciabilidade, inviolabilidade, universalidade, efetividade, interdependência e complementaridade. Para os direitos humanos, apesar das grandes diferenças existentes entre os indivíduos, sejam elas culturais ou biológicas, todos merecem ser tratados com respeito e dignidade. E em razão dessa igualdade social, nenhuma pessoa ou grupo, independente de gênero, cultura, etnia, orientação sexual, classe social, entre outros, pode afirmar-se superior a outro, como coloca Maria Amélia de Almeida Teles (2006).

O primeiro documento a tratar desses direitos foi a Declaração dos Direitos do Homem e do Cidadão, de 1789, garantindo os direitos fundamentais somente aos indivíduos do sexo masculino. Olympe de Gouges, revolucionária francesa que viveu entre 1748 e 1793, decidiu elaborar a Declaração dos Direitos da Mulher e da Cidadã, se contrapondo à primeira, sendo por isso perseguida e julgada pelo tribunal revolucionário sob o pretexto de rebeldia sendo, por fim, condenada à guilhotina (Teles, 2006). A sentença de condenação dizia que Olympe de Gouges "se imiscuiu nos assuntos da República, esquecendo-se das virtudes de seu sexo", como coloca Teles (2006: 19).

A Declaração Universal dos Direitos Humanos (ONU), de 1948, foi um dos primeiros documentos a tratar internacionalmente da questão dos direitos fundamentais, afirmando a neutralidade e igualdade entre os gêneros. Após, vieram muitas convenções e declarações que procuraram discutir especificamente o lugar da mulher nos direitos humanos, entre elas pode-se citar a Convenção sobre a Eliminação de Todas as Formas de Discriminação Contra as Mulheres (ONU, 1979). $\mathrm{O}$ artigo $1^{\circ}$ define a discriminação contra a mulher como sendo "[...] toda distinção, exclusão ou restrição baseada no sexo e que tenha por objeto ou resultado prejudicar ou anular o reconhecimento [...] dos direitos humanos e liberdades fundamentais [...]". Pode-se citar também a Declaração sobre a Eliminação da Violência contra as Mulheres (ONU, 1993), em que o Artigo $2^{\circ}$ expressa a consideração da mutilação genital feminina como uma "violência física, sexual e psicológica ocorrida no seio da família, [...]" (ONU, 1993).
Percebe-se uma grande evolução no tema dos direitos humanos, principalmente após a Segunda Guerra Mundial, em 1945. Com isso, as mulheres têm alcançado um maior empoderamento, podendo julgarem-se livres e independentes para tomarem suas próprias decisões, sem pressão social. Como este artigo abordará com a prática da mutilação genital feminina, ainda se vê um longo caminho pela frente até que haja uma verdadeira igualdade e neutralidade entre gêneros nos mais diversos países.

\section{Mutilação Genital Feminina}

Ao estudar a Mutilação Genital Feminina, nota-se a sua complexidade, tanto no que tange a prática em si, como o seu impacto no meio internacional. A MGF possui muitas variantes, e esta seção procura abordar alguns destes para melhor analisar a prática posteriormente. Serão discutidas questões como: o que é, seu histórico e possíveis origens, as justificativas para a sua propagação e as consequências sofridas pelas mulheres que passaram pela prática.

\section{O Que é a Mutilação Genital Feminina}

A Organização Mundial da Saúde (1997) determinou que a MGF se refere a todo procedimento que envolva a remoção do clitóris, seja total ou parcialmente, ou qualquer outro ferimento à genitália feminina e que não possua motivos médicos comprovados. A palavra mutilação é de grande importância nesse contexto, pois, além de denotar a gravidade do dano causado às mulheres, também reforça que é uma violência e uma violação dos seus direitos fundamentais (WHO, 2008). Também é importante por servir de ponto de inflexão entre esta prática e a circuncisão masculina, pois ambas se apresentam bem divergentes quanto as suas causas e consequências.

Quando analisada a questão da mutilação genital feminina, percebe-se que esta ocorre nas mais variadas comunidades e países, possuindo diferenças entre os procedimentos e as consequências causadas às mulheres (WHO, 2008). Cada região/etnia a realiza de uma determinada forma; portanto, julgou-se essencial classificar em quatro tipos distintos. A primeira descrição das mutilações ocorreu em 1995; porém, em 2007, a WHO (2008) verificou a necessidade de atualizar essas descrições. No Quadro 1 é possível constatar as diferenças 
existentes entre os quatro tipos de mutilação existentes hoje. Essa divisão ocorre por motivos científicos, mas também para facilitar a documentação e o mapeamento dos diversos formas de MGF (WHO, 2008).

\section{Quadro 1 - Classificação da Mutilação Genital Feminina}

\begin{tabular}{|c|c|c|c|}
\hline & TIPO & & SUBTIPO \\
\hline \multirow{2}{*}{ TIPO I } & \multirow{2}{*}{$\begin{array}{l}\text { Remoção total ou } \\
\text { parcial do clitóris } \\
\text { e/ou prepúcio } \\
\text { (clitoridictomia). }\end{array}$} & (a) & $\begin{array}{l}\text { Remoção do clitóris } \\
\text { ou do prepúcio } \\
\text { somente. }\end{array}$ \\
\hline & & (b) & $\begin{array}{l}\text { Remoção do clitóris } \\
\text { com o prepúcio. }\end{array}$ \\
\hline \multirow{3}{*}{ TIPO II } & \multirow{3}{*}{$\begin{array}{l}\text { Remoção total ou } \\
\text { parcial do clitóris } \\
\text { e dos pequenos } \\
\text { lábios, com ou sem } \\
\text { a amputação dos } \\
\text { grandes lábios. }\end{array}$} & (a) & $\begin{array}{l}\text { Remoção dos } \\
\text { pequenos lábios } \\
\text { somente. }\end{array}$ \\
\hline & & (b) & $\begin{array}{l}\text { Remoção total ou } \\
\text { parcial do clitóris e } \\
\text { dos pequenos lábios. }\end{array}$ \\
\hline & & (c) & $\begin{array}{l}\text { Remoção total ou } \\
\text { parcial do clitóris, } \\
\text { dos pequenos e dos } \\
\text { grandes lábios. }\end{array}$ \\
\hline \multirow[b]{2}{*}{ TIPO III } & \multirow{2}{*}{$\begin{array}{l}\text { Estreitamento do } \\
\text { orifício vaginal, } \\
\text { reunindo os } \\
\text { pequenos e/ou } \\
\text { grandes lábios, } \\
\text { formando um tipo de } \\
\text { cobertura, com ou } \\
\text { sem a amputação do } \\
\text { clitóris (infibulação). }\end{array}$} & (a) & $\begin{array}{l}\text { Remoção e junção } \\
\text { dos pequenos lábios. }\end{array}$ \\
\hline & & (b) & $\begin{array}{l}\text { Remoção e junção } \\
\text { dos grandes lábios. }\end{array}$ \\
\hline TIPO IV & $\begin{array}{l}\text { Não classificado: } \\
\text { todos os outros } \\
\text { procedimentos } \\
\text { prejudiciais } \\
\text { à genitália } \\
\text { feminina, sem } \\
\text { motivos médicos } \\
\text { comprovados. } \\
\text { Exemplos: punção, } \\
\text { perfuração, incisão, } \\
\text { raspagem e } \\
\text { cauterização. }\end{array}$ & & - \\
\hline
\end{tabular}

Fonte: Adaptado pela autora com base em WHO (2008, p. 24).
Segundo Donald Barstow (1999), as condições em que esta prática é realizada podem ser muito inseguras, devido principalmente aos equipamentos utilizados para tal, sendo realizada, na maioria dos casos, por parteiras e curandeiros. Esta adversidade também se mostra aparente ao se tentar precisar os motivos que levaram à prática, assim como sua origem.

\section{Origem da Mutilação Genital Feminina}

De acordo com Barstow (1999), a primeira menção à mutilação genital feminina foi em torno de 450 a.C., pelo historiador grego Heródoto. No entanto, não há uma origem concreta para a prática, existindo muitas especulações quanto ao seu início. Muitos acreditam (Barstow, 1999; WHO, 2001) que essa remonta ao Egito antigo, devido a exames feitos em múmias daquela época, que mostram que a MGF era uma prática comum, principalmente entre a nobreza.

Existem duas explicações possíveis quanto ao motivo da mutilação genital ter se iniciado no Egito. A primeira delas refere-se à herança da propriedade e dos títulos de nobreza, onde a mutilação genital feminina teria surgido como uma forma de assegurar a legitimidade das reivindicações ao trono pelo faraó. Barstow (1999) coloca que a segunda vertente seria quanto à preocupação histórica masculina com a fidelidade feminina. Da mesma forma que na Europa da época das Cruzadas as mulheres usavam cintos de castidade de metal, os egípcios teriam feito uso da MGF com o mesmo propósito (Barstow, 1999).

Barstow (1999), descreve a crença dos egípcios antigos de que o corpo humano é, na verdade, bissexual, e deveria ser realizada a circuncisão masculina e feminina (como eles a denominavam na época) para que o corpo se tornasse completamente de um único gênero. Esta crença da bissexualidade dos corpos pode ser verificada nos deuses egípcios daquele período, que eram representados com órgãos sexuais de ambos os sexos.

\section{Justificativas Para a Mutilação Genital Feminina}

Dentre os motivos trazidos por muitos autores (Morgan \& Steinem, 1997; Barstow, 1999; Cook et al, 2002; UNICEF, 2013) pode-se citar a perspectiva de casamento 
e a preservação da virgindade como as principais. Como o matrimônio, em muitas comunidades onde é praticada a MGF, é o principal meio de sobrevivência econômica da mulher, muitos pais optam pela mutilação genital como uma maneira de garantir um futuro melhor para suas filhas (Morgan \& Steinem, 1997; Cook et al, 2002).

Outra justificativa bastante mencionada, especialmente nos dados compilados pelo Fundo das Nações Unidas para a Infância (UNITED NATIONS CHILDREN'S FUND - UNICEF, 2013), é quanto à aceitação social. A decisão de submeter a si ou suas filhas à prática, está ligada com a expectativa de como os outros esperam que as meninas/mulheres se comportem. Essa prática também teria como um dos objetivos ensiná-las a serem passivas e submissas aos homens, e até mesmo a se comportarem de maneira moralmente virtuosa, segundo esses valores (UNICEF, 2013).

Existem também algumas justificativas ligadas à sexualidade feminina. A primeira delas discorre quanto à crença do desejo sexual feminino ser muito maior que o masculino, o que a levaria à promiscuidade e a demandar maior atenção amorosa e sexual do seu marido (Morgan \& Steinem, 1997; Cook et al, 2002; UNICEF, 2013). A Mutilação Genital Feminina serviria como um maneira de prevenir que as mulheres se tornem adúlteras em seus relacionamentos, mostrando que esta prática busca o controle sobre a sexualidade da mulher em sociedades patriarcais, onde há uma dominação masculina (Cook et al, 2002).

São muitas as justificativas para perpetuar essa prática, apesar de toda literatura existente que coloca o quanto essa afeta negativamente as mulheres. $\mathrm{O}$ trecho a seguir resume esta questão:

sejam quais forem as justificativas para esses esforços de fazer com que os corpos das mulheres entrem em conformidade com as expectativas sociais, podemos explorar suas razões reais somente dentro do contexto do patriarcado. Ele deve controlar o corpo feminino como meio de reprodução e, logo, represar a independência da sexualidade feminina. Ambos os motivos são reforçados pelas recompensas e punições socioeconômicas (Morgan \& Steinem, 1997: 370).
Como visto, existe uma diversidade de razões para a realização, ainda hoje, desta prática. Porém, o que todas têm em comum é o fato delas contribuírem para o sofrimento destas meninas e mulheres, tendo em vista que a mutilação genital traz sérias consequências para a saúde feminina.

\section{Consequências da Mutilação Genital Feminina}

As implicações da mutilação genital feminina são muitas e variam de acordo com o tipo e a severidade do procedimento realizado (WHO, 1997; Reyners, 2004). Marcel Reyners (2004) classifica as complicações sofridas pelas mulheres em físicas, emocionais e psicossexuais. Analisando primeiramente as consequências físicas, Reyners (2004) as divide em três fases: imediatas, tardias e obstétricas.

Como complicações imediatas, quase todas experimentam dor e sangramento, em alguns casos podem haver hemorragia, tétano, infecções e transmissão do Vírus da Imunodeficiência Humana - HIV (WHO, 1997; Barstow, 1999; UNICEF, 2013). As consequências a longo prazo são mais complicadas de determinar, devido ao tempo decorrido desde a prática. Porém, dentre elas pode-se citar a diminuição do prazer sexual, formação de queloide (crescimento anormal de tecido cicatrizado, em um ferimento já curado), infecções urinárias crônicas e dificuldades para urinar e menstruar, dentre outras (Barstow, 1999; UNICEF, 2013). A mutilação genital também aumenta os riscos para a gestante e o feto. Segundo Jane Cottingham \& Eszter Kismodi (2009), bebês de mães que passaram pela MGF têm de $15 \%$ a $55 \%$ mais chances de vir a falecer logo após o parto. Este risco varia de acordo com o tipo de mutilação pelo qual a gestante passou. Reyners (2004) acrescenta como complicações obstétricas o trabalho de parto prolongado, exames e resultados neonatais prejudicados, parto dificultado e danos psicológicos às gestantes.

Quanto às consequências psicológicas, as mulheres que passaram pela MGF apresentam estresse pós-traumático, ataques de ansiedade, e depressão, chegando a ter dificuldade de relacionar-se amorosa e sexualmente com seus parceiros (as). São várias as consequências psicossexuais decorrentes da mutilação genital feminina, tais como diminuição do prazer sexual, dispareunia, ou dor durante a relação sexual 
e vaginismo (contração vaginal involuntária, impedindo a relação sexual), conforme enumeram Morgan \& Steinem (1997) e Reyners (2004).

As consequências da mutilação genital feminina podem ser difíceis de determinar em muitos casos. O UNICEF (2013) afirma que isso se deve ao fato de que, em localidades onde esta prática é tida como normal, certas consequências também o são. Por este motivo, estudos feitos por médicos e hospitais especializados, assim como por entidades internacionais têm sido desenvolvidos para fornecer um melhor mapeamento das consequências trazidas pela mutilação genital feminina (UNICEF, 2013). Estas pesquisas mostram-se importantes ao compilar os dados sobre a MGF e também verificar a evolução da prática, se está diminuindo ou não, e em quais locais ocorrem estas mudanças.

\section{Mutilação Genital Feminina na África}

A mutilação genital feminina mostra-se bastante complexa em toda sua abrangência nas populações. Existem muitas variantes que acabam por influenciar esta tradição, tanto no que leva à prática nestas comunidades, quanto à forma como ela ocorre em cada local (Gruenbaum, 2001). Fatores como etnia, meio rural-urbano e educação acabam por influir na prevalência da MGF em cada localidade, já elementos como idade e justificativas, além de atuar também na concentração da prática, no entanto em menor importância, revelam-se mais atuantes no sentido de ajudar o mapeamento e o entendimento da prática.

\section{Fatores-chave para a Prevalência da Prática}

Segundo o UNICEF (2013) a MGF é encontrada em maior concentração em 29 países africanos, principalmente do norte do continente. Muitos autores (Gruenbaum, 2001; Yoder et al, 2004; UNICEF, 2005a, 2005b) colocam que, dentre todos os fatores-chave da prática, a etnia aparece como um dos que melhor explicam as diferenças encontradas dentro dos países onde é praticada a MGF. Ellen Gruenbaum (2001) disserta sobre a MGF estar profundamente entranhada com a identidade étnica da população e sobre a importância de entender essa questão para compreender os motivos da resistência encontrada em mudar tais ritos.
Nos países africanos que possuem maior concentração da população feminina mutilada, o UNICEF (2013) realizou uma pesquisa entre mulheres e meninas de 15-49 anos de idade, onde buscou mapear as estatísticas referentes à prática. A prevalência da MGF dentro dos países varia, principalmente devido ao fator etnia, porém, algumas outras razões também são encontradas, como a escolaridade e o local de residência. Quando analisada a etnia percebe-se as disparidades que essas geram, principalmente onde as taxas não são muito altas. O UNICEF $(2005 b ; 2013)$ coloca como exemplo a porcentagem de mulheres mutiladas em Eritréia e Mali passarem dos $80 \%$, portanto, não existiria muita diferença entre os grupos internos, dada a alta concentração da MGF nesses países como um todo. Já no Quênia os números variam de $1 \%$ a $95 \%$ de prevalência da Mutilação Genital Feminina entre as etnias.

Ao analisar os números totais encontrados, em grande parte do continente africano a concentração da prática é superior a $51 \%$ do total da população feminina. Estima-se que entre 100 e 140 milhões de meninas e mulheres já passaram pela MGF somente no norte do continente africano (UNICEF, 2013). Os autores Stanley Yoder \& Shane Khan (2008) avaliam que 91,5 milhões de mulheres e meninas africanas acima dos 9 anos de idade estão vivendo com as consequências da mutilação genital atualmente e que 3 milhões correm o risco de passar por esta prática a cada ano; deste total, 1 em cada 5 vive no Egito, segundo o UNICEF (2013).

Em alguns países africanos a prática é quase universal. No Egito, onde se acredita que a mutilação genital feminina tenha se iniciado, a MGF chega a atingir 91\% da população (UNICEF, 2013). Somália, Guiné e Djibouti apresentam números similares a esse, sendo estes 98\%, 96\% e 93\%, respectivamente (UNICEF, 2013). Esses são os únicos países africanos que apresentam uma taxa superior aos 90\%. Já em Camarões e Uganda, o número cai para apenas $1 \%$ (UNICEF, 2013).

Além da questão da etnia, também devem ser levados em conta outros fatores, que podem ser demonstrados através de indicadores como o Índice de 
Desenvolvimento Humano ${ }^{1}$ (IDH). No caso dos países citados acima, Guiné apresenta os piores números, apresentando um IDH de 0,392, segundo o Programa das Nações Unidas para o Desenvolvimento (UNDP - sigla em inglês, 2014), sendo que a Somália não possui dados computados. O IDH fornece uma visão do desenvolvimento político e econômico do país, servindo, portanto, de complemento explicativo para as diferenças encontradas entre as taxas de MGF. A relação entre este índice e a mutilação genital nem sempre é percebida, um exemplo disso é o Egito, que possui o melhor IDH entre os países estudados, chegando a 0,682 (UNDP, 2014). Importante ressaltar que este indicador mede o desenvolvimento de um país, fazendo uso de alguns medidores que acabam influenciando as taxas de mutilação genital, como a educação e as condições econômicas (UNICEF, 2013; UNDP, 2014).

O Fórum Econômico Mundial - FEM (2016) lançou um relatório que mede as desigualdades entre gêneros em questões como educação, economia, política e saúde. O FEM busca, através deste indicador, trazer uma maior consciência para estes temas, assim como marcar o progresso em direção a uma maior igualdade entre os sexos (FEM, 2016). Entre os países citados acima, Egito, num ranking de 142 nações, encontra-se em $132^{\circ}$ lugar, e Guiné em $122^{\circ}$. Já Uganda, apesar de ainda haver uma grande disparidade entre gêneros, já está bem acima nesta lista, ocupando $61^{\circ}$ lugar.

Em alguns países, onde a concentração de Mutilação Genital Feminina ébaixa, pode haver uma grande variação entre as regiões deste mesmo país (UNICEF, 2013). Quanto à questão étnica no Senegal, por exemplo, a média de meninas que já teve sua genitália mutilada é $26 \%$; porém, na região de Diourbel o percentual cai para $1 \%$ (esta região fica na costa do Senegal e é ocupada pela etnia Bantoid²), já em Kedougou (na parte leste, próximo a Mali) sobe para $92 \%$. Importante destacar que a parte leste

$1 \mathrm{O}$ IDH é um indicador que mede o desenvolvimento de um país, fazendo uso da expectativa de vida ao nascer, a educação e as condições econômicas para chegar ao índice final de um país. Ele vai de 0 a 1 , e quanto mais alto, mais desenvolvido é o Estado, e quanto mais próximo ao zero, piores são as condições de vida (UNDP, 2014).

2 UNESCO (1984) esclarece que os Bantoids descendem da etnia Bantu, sendo que esta última é uma das mais antigas do continente africano. Os Bantus não possuem histórico de praticar a MGF, exemplo disso é que a parte do continente mais ocupada por eles, o sul da África, não possui dados que comprovem a realização da prática. do Senegal, cujo percentual sobe drasticamente, faz divisa com Mali, onde $89 \%$ da população feminina já passou pela MGF, e esta região de fronteira é habitada pela etnia Mande 3 . Segundo Stanley Yoder et al (2004), essa prática ocorre com maior frequência nas áreas rurais, também devido à baixa escolaridade nessas áreas. Segundo esses autores, somente três países apresentaram maiores taxas nas áreas urbanas, são eles: norte do Sudão, Burkina Faso e Nigéria, sendo que o fator etnia explicaria as altas taxas nas cidades desses locais.

É imperativo verificar as diferenças que existem dentro dos próprios países. O contraste mais expressivo encontra-se nos dados recolhidos na Etiópia, no ano de 2000 , onde o percentual chega a $100 \%$ nas duas etnias com maior número de MGF, e $0,8 \%$ nas duas com menor. Já países como Guiné não apresentam muita diferença interna, atingindo $99,7 \%$ nas maiores etnias e $94,2 \%$ nas menores (UNICEF, 2005a).

\section{Justificativas para a Continuidade da Prática}

Apesar das justificativas variarem muito de local para local, elas seguem alguns temas em comum, como a status da mulher, aceitação social, perspectivas de casamento e preservação da virgindade, segundo o UNICEF (2005a). Os autores Gerry Mackie \& John LeJeune (2009) classificam essas razões em três níveis: patriarcado, cultura (incluindo religião e etnia) e matrimônio.

Segundo a visão feminista, a Mutilação Genital Feminina seria uma ação que objetiva, ou tem por consequência, a opressão da mulher nestas sociedades (Morgan \& Steinem, 1997; Mackie \& LeJeune, 2009). Esta prática é motivada pela dominação masculina sobre a mulher e perpetuada pelas grandes desigualdades existentes entre os gêneros e sexos. Conforme Mackie \& LeJeune (2009), essa não pode ser considerada a única causa e justificativa, tendo em vista que existe um grande número de sociedades que não são praticantes da MGF e que também são patriarcais.

Quando analisada a questão cultural, tem-se que a MGF é uma norma social (Mackie \& LeJeune, 2009),

\footnotetext{
3 De acordo com UNESCO (1984), na etnia Mande o reinado é patrilinear, possuindo uma sociedade bastante hierárquica, constituída por castas e possuindo escravos.
} 
sendo uma regra comportamental que é seguida devido à crença de que esta é a ação esperada pela sociedade. Isto é, uma das explicações para a prática ainda existir é a aceitação social, ou como uma forma de reconhecer os membros de uma mesma cultura/etnia (UNICEF, 2013). A mutilação genital seria mais uma maneira de pertencimento a uma sociedade do que de diferenciação.

Nos estudos de Mackie \& LeJeune (2009), a perspectiva de casamento é um dos motivos mais citados para a prática, principalmente pelo caráter socioeconômico adquirido nesses locais. Em muitas dessas sociedades, os costumes econômicos patriarcais fazem com que o matrimônio seja necessário para que a mulher tenha segurança financeira. Segundo o UNICEF (2013), em muitas comunidades tradicionais da África Subsaariana, ainda há pagamentos de dotes para a família da noiva (conforme verificado em vilas egípcias e na Nigéria, por exemplo) e, como exemplificado por UNICEF (2005a), entre alguns grupos étnicos da Tanzânia, o valor pago por uma noiva que passou pela MGF é muito maior do que o de uma que não tenha passado pela prática.

\section{Idades Para a Prática da Mutilação Genital Feminina}

É importante o conhecimento sobre a idade em que as meninas estão mais vulneráveis a passar pela mutilação genital para a criação de políticas e campanhas a favor da erradicação da prática, assim como monitorar a tendência ao longo dos anos (Yoder et al, 2004; UNICEF, 2013). A MGF geralmente ocorre entre meninas de 0-15 anos de idade. Em países como Mali, Nigéria, Eritréia, Gana e Mauritânia, mais de $80 \%$ das meninas é mutilada antes de completar 5 anos de idade. Já no Quênia, por exemplo, em torno de $15 \%$ delas passa pela MGF somente após os 15 anos de idade, quando é atingida a puberdade ou como forma de preparação para o casamento (UNICEF, 2013).

Determinar a idade também se mostra importante ao analisar o impacto das consequências, principalmente psicológicas, para estas meninas. Independentemente da idade, as implicações sofridas ainda são fortes, tanto para a psique da menina, quanto para o físico e psicossexual destas. Porém, Yoder et al (2004) afirmam que quando a mutilação ocorre nos primeiros meses de vida, as memórias referentes ao evento são mínimas, quando comparadas com o abalo emocional sofrido por adolescentes e mulheres adultas. O UNICEF (2005a) frisa que, devido a prática não deixar de ser uma violência contra mulheres e crianças, independentemente da idade, a Mutilação Genital Feminina fere os direitos dessas.

\section{Considerações Finais}

Conforme visto ao longo deste artigo, a mutilação genital feminina mostra-se uma prática sexista ao negar à grande parte da população feminina africana os seus direitos mais básicos, tais como saúde, não-violência e não invasão de seus corpos. Este costume também viola a autonomia dessas mulheres, pois estas muitas vezes não têm direito de escolha sobre seus corpos ou sobre os de suas filhas.

As justificativas utilizadas para a perpetuação da prática, como mostra Mackie \& LeJeune (2009), são, em sua grande maioria, patriarcais. Isso significa dizer que a prática serve também como forma de controlar os corpos das mulheres e, consequentemente, a sua autonomia sobre outros interesses diversos. Apesar de em alguns casos ser escolha dessas mulheres passar pela Mutilação Genital Feminina, tendo em vista que esta concederia melhores oportunidades econômicas através do casamento, por exemplo, esta prática também é uma forma de fazer com que os corpos das mulheres atendam às expectativas externas a elas, e, de certa forma, seria também, uma maneira de as manter passivas e submissas às vontades e escolhas da população masculina de suas comunidades, conforme exposto anteriormente.

Ao controlar a sexualidade feminina, conforme expõe Morgan \& Steinem (1997), controla-se também grande parte da sua independência e liberdade, e, quando esta opta por não participar da prática, tem-se uma grande pressão social agindo como punição. Quando estas mulheres consentem com a Mutilação Genital Feminina, deve-se haver um questionamento sobre até que ponto esta é uma escolha livre de pressões externas.

Afunção dos Estados e das entidades internacionais que trabalham com este tema é justamente educar essas comunidades para que saibam as consequências que a MGF traz para as essas mulheres. Deve-se mostrar também que em uma comunidade, ou em um país, onde as mulheres conseguem ser mais independentes e desenvolvidas, elas ajudam o país a crescer, elas ajudam a desenvolver 
a nação, tanto econômica, social e politicamente. Os dados trazidos pelos relatórios citados ao longo do artigo corroboram com isso. Os países mais desenvolvidos são aqueles em que as mulheres tem maior liberdade política, econômica, educacional e mesmo sexual.

\section{Referências}

BARSTOW, Donald. (1999). "Female Genital Mutilation: the penultimate gender abuse". Child abuse \& neglect, $\mathrm{n}$. 5, 23: p. 501-510.

COOK, Rebecca et al. (2002). "Female Genital Cutting (Mutilation/Circumcision): ethical and legal dimensions". International Journal of Gynecology and Obstetrics, 79: p. 281-287.

COTTINGHAM, Jane \& KISMODI, Eszter. (2009). "Protecting Girls and Women from Harmful Practices Affecting Their Health: are we making progress?". International Journal of Gynecology and Obstetrics, 106: p. 128-131.

\section{DEPARTMENT FOR INTERNATIONAL}

DEVELOPMENT (DFID). (2013). Towards Ending Female Genital Mutilation/Cutting in Africa and Beyond. Londres: DFID.

FARGANIS, Sondra. (1994). "Postmodernism and Feminism”. In: DICKENS, David R. \& FONTANA, Andrea. (Org.). Postmodernism and Social Inquiry. New York: The Guilford Press, p. 101-126.

FÓRUM ECONÔMICO MUNDIAL (FEM). (2016). The Global Gender Gap Report 2016. Geneva: FEM.

FRIEDAN, Betty. (2001). The Feminine Mystique. $1^{\mathrm{a}}$ edição. New York: Norton.

GRUENBAUM, Ellen. (2001). The Female Circumcision Controversy: an anthropological perspective. Filadélfia, University Pennsylvania Press.
HANISCH, Carol. (1970). “The Personal Is Political”. In: FIRESTONE, Shulamith \& KOEDT, Anne. Notes From the Second Year: women's liberation: major writing of the radical feminists. New York: Radical Feminism.

KROLOKKE, Charlotte \& SORENSEN, Anne Scott. (2005). "Three Waves of Feminism". In: . Gender Communication Theories and Analyses. Thousand Oaks: SAGE Publications, Inc., p. 1-24.

MACEDO, Ana Gabriela. (2006). "Pós-feminismo". Estudos Feministas, Florianópolis, n. 3, 14: p. 813-817, set-dez.

MACKIE, Gerry \& LeJEUNE, John. (2009). Social Dynamics of Abandonment of Harmful Practices: a new look at the theory. Special Series on Social Norms and Harmful Practices. Innocenti Working Paper. Florence: UNICEF.

MONTE, Izadora. "O Debate e os Debates: abordagens feministas para as Relações Internacionais". Revista Estudos Feministas, n. 1, 21: p. 59-80.

MORGAN, Robin \& STEINEM, Gloria. (1997). "O Crime Internacional da Mutilação Genital”. In: STEINEM, Gloria. Memórias da transgressão: momentos da história da mulher do século XX. Rio de Janeiro: Record.

ORGANIZAÇÃO DAS NAÇÕES UNIDAS (ONU). (1993). Declaração Sobre a Eliminação da Violência contra as Mulheres. Disponível em: <http:// direitoshumanos.gddc.pt/3_4/IIIPAG3_4_7.htm >. Acesso em: 14 dez. 2016.

(1979). Convenção Sobre a Eliminação de Todas as Formas de Discriminação Contra as Mulheres. Disponível em: <http://www.unfpa.org.br/Arquivos/ cedaw.pdf $>$. Acesso em: 14 dez. 2016.

(1948). Declaração Universal dos Direitos Humanos. Disponível em: <http://www.onu.org.br/ img/2014/09/DUDH.pdf > . Acesso em: 14 dez. 2016. 
PISCITELLI, Adriana. (2002). "Recriando a (categoria) mulher?". In: ALGRANTI, Leila (Org.). A Prática Feminista e o Conceito de Gênero. Campinas: IFCHUnicamp.

REYNERS, Marcel. (2004). "Health Consequences of Female Genital Mutilation". Reviews in Gynecological Practice, n. 4, 4: p. 242-251.

TELES, Maria Amélia de Almeida. (2006). O Que São Direitos Humanos das Mulheres. São Paulo: Brasiliense.

\section{UNITED NATIONS CHILDREN'S FUND (UNICEF).}

(2013). Female Genital Mutilation/Cutting: a statistical overview and exploration of the dynamics of change. New York: UNICEF. Disponível em: <http://data.unicef.org/ wp-content/uploads/2015/12/FGMC_Lo_res_Final_26. pdf $>$. Acesso em: 14 dez. 2016.

. (2005a). Changing a Harmful Social Convention:

female genital mutilation/cutting. Florença: UNICEF. Disponível em: $<$ https://www.unicef-irc.org/publications/ pdf/fgm_eng.pdf $>$. Acesso em: 14 dez. 2016.

. (2005b). Female Genital Mutilation/Cutting: a statistical exploration. Florença: UNICEF. Disponível em: <https://www.unicef.org/publications/files/FGM-C_ final_10_October.pdf $>$. Acesso em: 14 dez. 2016.

UNITED NATIONS DEVELOPMENT PROGRAMME (UNDP). (2014). Human Development Report 2014: sustaining human progress. New York: UNDP.

UNITED NATIONS EDUCATIONAL, SCIENTIFIC AND CULTURAL ORGANIZATION (UNESCO). (1984). General History of Africa IV: Africa from the twelfth to the sixteenth century. Paris: UNESCO. Disponível em: $<$ http://unesdoc.unesco.org/ images/0018/001842/184287eo.pdf $>$. Acesso em: 14 dez. 2016.
WORLD HEALTH ORGANIZATION (WHO) (Org). (2008). Eliminating Female Genital Mutilation: an interagency statement UNAIDS, UNDP, UNECA, UNESCO, UNFPA, UNHCHR, UNHCR, UNICEF, UNIFEM, WHO. Genebra: WHO. Disponível em: $<$ http:// www.un.org/womenwatch/daw/csw/csw52/statements missions/Interagency_Statement_on_Eliminating_FGM. pdf>. Acesso em: 14 dez. 2016.

(2001). Female Genital Mutilation: a student's manual. Genebra: WHO. Disponível em: <http://www. who.int/gender/other_health/Studentsmanual.pdf $>$. Acesso em: 14 dez. 2016.

(Org). (1997). Female Genital Mutilation: a joint WHO/UNICEF/UNFPA statement. Genebra: WHO.

YODER, Stanley et al. (2004). Female Genital Cutting in the Demographic and Health Surveys: a critical and comparative analysis. Maryland: DHS. Disponível em: $\quad<$ http://dhsprogram.com/pubs/pdf/CR7/CR7.pdf $>$. Acesso em: 13 dez. 2016.

YODER, Stanley \& KHAN, Shane. (2008). Numbers of Women Circumcised in Africa: the production of a total. Maryland: DHS. Disponível em: $<$ http://dhsprogram.com/ pubs/pdf/WP39/WP39.pdf>. Acesso em: 13 dez. 2016.

Recebido em: 16/03/2017.

Aceito: 13/07/2017. 